\title{
Dynamic Characteristics Analysis on MHTGR Plant's Secondary Side Fluid Flow Network
}

\author{
Maoxuan Song, Zhe Dong \\ Institute of Nuclear and New Energy Technology, Collaborative Innovation Center of Advanced Nuclear Energy \\ Technology of China, Key Laboratory of Advanced Reactor Engineering and Safety of Ministry of Education, \\ Tsinghua University, Beijing, China \\ Email:smx14@mials.tsinghua.edu.cn,dongzhe@mail.tsinghua.edu.cn
}

Received 30 March 2016; accepted 26 July 2016; published 29 July 2016

\begin{abstract}
Multipe NSSS (Nuclear Steam Supply System) modules use the common feeding-water system to drive the common turbine power generation set. The SSFFN (secondary side fluid flow network) of MHTGR plant has features i.e. strong-coupling and nonlinearity. A wide range of power switching operation will cause unsteady flow, which may destroy the working elements and will be a threat for normal operation. To overcome those problems, a differential-algebraic model and PI controllers are designed for the SSFFN. In MATLAB \SIMULINK environment, a simulation platform is established and used to make a simulation of SSFFN of a MHTGR plant with two NSSS modules, which uses feedwater valves to control the mass flow rate in each module instead of feedwater pump. Results reflect good robustness of controllers.
\end{abstract}

\section{Keywords}

MHTGR Plant, Secondary Side Fluid Flow Network, a Differential-Algebraic Model, PI Controllers

\section{Introduction}

As the fourth generation of nuclear power system, the modular high-temperature gas-cooled reactor (MHTGR) plant receives extensive attention from the world's nuclear power industry due to its inherent safety and economic efficiency. As characterized by modularization and miniaturization, MHTGR uses helium as coolant and uses graphite as moderator and structural materials. Its fuel elements contain thousands of ceramic mould package particles. Its core outlet helium temperature can reach $700^{\circ} \mathrm{C}-950^{\circ} \mathrm{C}$ [1] [2]. In order to own inherent safety, the core density and geometry size is designed smaller, thus the highest temperature of fuel elements will not surpass the limit temperature $1620^{\circ} \mathrm{C}$ [3]. In order to improve economic competitiveness, MHTGR plant adopts modularization construction, using multiple NSSS (Nuclear Steam Supply System) modules to feed one steam turbine generator set, e.g. HTR-PM plant. HTR-PM plant uses two NSSS modules to feed one steam turbine set. Each NSSS module contains a pebble-bed reactor, whose heat power is $250 \mathrm{MW}_{\text {th }}$, a helium fan, a once-through steam generator and corresponding pipes. Steam generated by each NSSS flows into the same steam header and then flows into the steam turbine generator set after uniform mixed in the steam header. Because the two modules use the same feed-water system to feed the same steam turbine generator set, the secondary side fluid flow 
network (SSFFN) between the two modules has features e.g. strong-coupling, nonlinearity, etc. A wide range of power switching operation may cause unsteady fluid flow, which may destroy working components. In order to control modules coordinately and ensure MHTGR plant's safety, it is meaningful to make a research on the dynamic characteristics of the SSFFN.

Fluid Flow networks (FFNs) widely exist in industrial engineering, e.g. mine ventilation, water supply and drainage system and oil gas industry, etc. [4] [5]. Research on FFNs began in study on controlling mine ventilation system in the 1970s-1980s. It is based on the fluid dynamics and can be divided into two categories, active control and passive control methods. The difference between the two is that active control method uses the fluid resistance characteristics and relies on auxiliary control operations [6] [7]. Kocic [8] pioneered the research on FFNs. He approximately regarded the mine ventilation system as a lumped parameter dynamic model and designed a linear feedback flow controller by using branch fluid dynamics. However, lacking of graph properties, he ignored nonlinear features of FFNs. By incorporating graph properties and branch fluid dynamics, Krstić [9] put forward the nonlinear non-minimal model and minimal model. Both models can guarantee the closed-loop global exponential stability of the FFNs. Dong Zhe [10] proposed distributed control method based on the minimal model [9]. The method is formed by the flow controller on the network of independent branch. He realized distributed control of FFNs and guaranteed the global asymptotic stability of the closed-loop system.

In this paper, a differential-algebraic model of MHGTR plant's SSFFN, based on Kirchhoff's law and branch dynamics, and PI controller sensuring globally asymptotic stability are given. What's more, a simulation platform was established, which can be used for simulation experiments on SSFFN, which has more NSSS modules.

\section{Model of SSFFN}

\subsection{Structure of the SSFFN}

From Figure 1, We can see two type plants with similar structure. NSSS modules in left are fed by separate feedwater pumps. The SSFFN comprises a steam heater, a steam turbine generator set, condenser, LP heater, HP heater, deaerator, pipes and valves etc. The mass flow rate in each NSSS module is controlled by feedwater pumps and flow changes in one NSSS module doesn't influence other modules'. The plant in right uses the same feedwater pump to feed water for all NSSS modules and uses valves instead of pumps to control the mass flow rate in NSSS modules. Like SSFFN in left, the flow's change in one NSSS module doesn't influence other modules', but it does impact on other pipes' flow in the SSFFN. Thus, control on SSFFN is a multivariable control problem as the SSFFN has strong-coupling and nonlinear features. This paper will make analysis on SSFFN in right.

\subsection{Branch Dynamic Equation}

Assuming that all flow dynamic parameters in pipes are evenly distributed on the radial cross section. Under the assumption, the flow in pipes can be seen as a one-dimensional flow. We can use the average values of dynamic parameters of the radial cross section and branch dynamic equation is deduced as Equation (1).

$$
d Q_{j} / d t+K_{j} R_{j}\left|Q_{j}\right| Q_{j}=K_{j} H_{j}
$$

where $Q_{j}, R_{j}, H_{j}$ and $K_{j}$ is the mass flow rate, the resistance, the pressure drop, the inertia coefficient of the branch $j, j=1, \cdots, N$ and $N$ is the branch number of network.

\subsection{Graph Features}

Making a topology analysis on the structure of the SSFFN of MHTGR plant shown in right in Figure 1.

There are $n+3$ nodes and $2 \times n+2$ branches (including 1 pump branch) in this network shown in Figure 2 . The SSFFN can be divided into a tree containing the feedwater pump branch and its complement, the co-tree whose branches are referred to as links. From Figure 2, it is clear that the number of the link is $n$. In Figure 2, branches $Q_{1}-Q_{n}$ representing $1 \#$-n\# NSSS module are links and the rest are trees. Branch $Q_{n+1}$ represents steam turbine generator set. Branch $Q_{f}$ represents feedwater pump branch which is connected to the node 1 . Branches $Q_{v 1}-Q_{v n}$ represents feeding valve branches. Like an electrical network, the SSFFN must satisfy Kirchhoff's current law (KCL) and voltage law (KVL) [9]. Based on Kirchhoff's current law, we have 


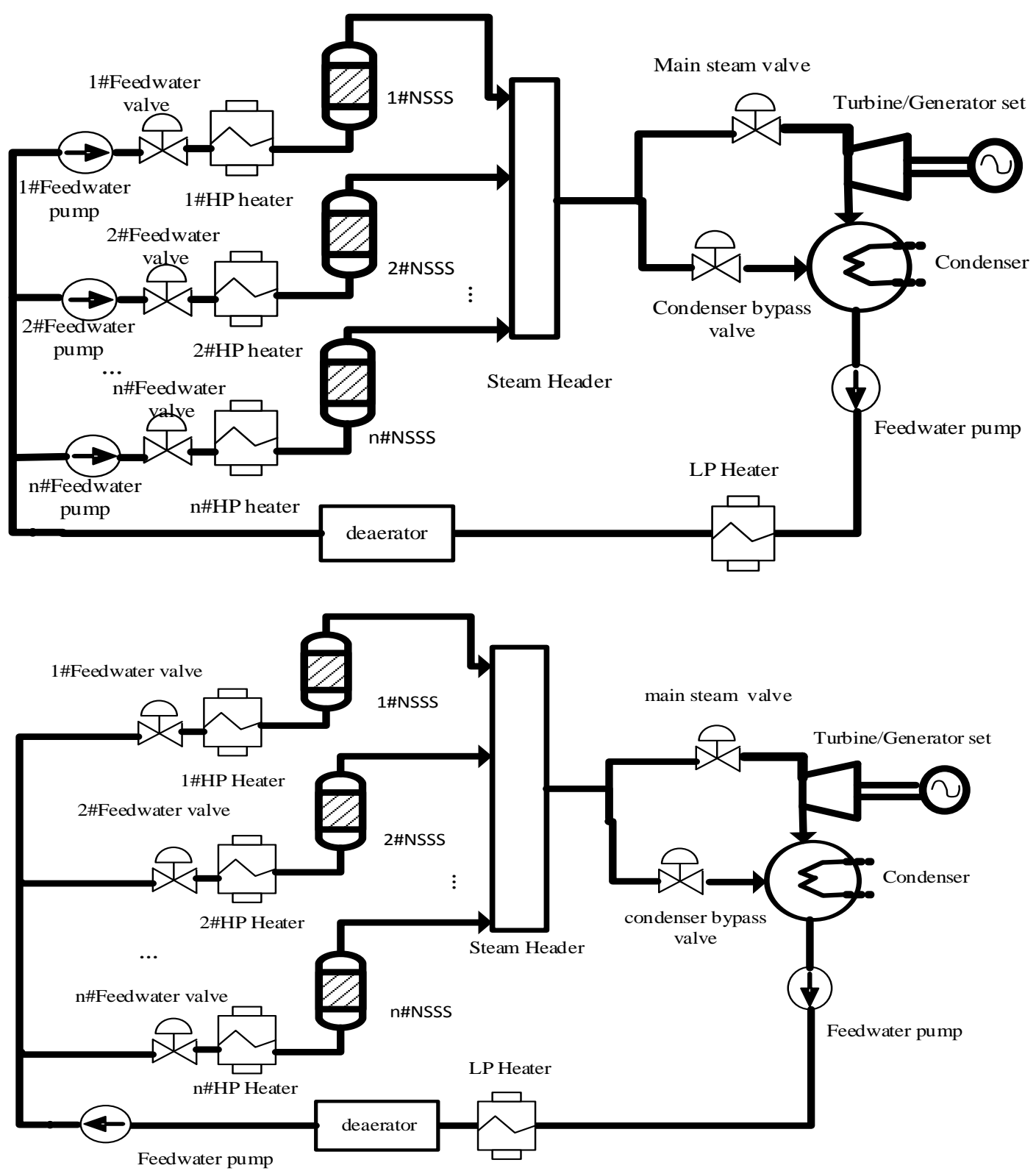

Figure 1. MHTGR plant.

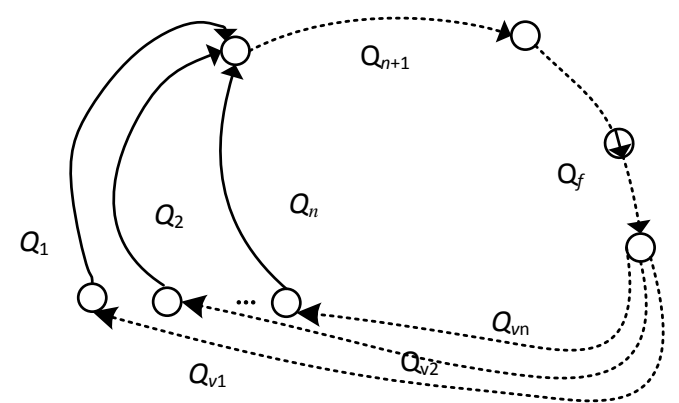

Figure 2. Topology of the SSFFN. 


$$
\left[\begin{array}{ccc}
\boldsymbol{E}_{\mathrm{Q} c} & \boldsymbol{E}_{\mathrm{Q} a} & \boldsymbol{O}_{(n+1) \times 1} \\
-\boldsymbol{e}_{\mathrm{Qfc}} & -\boldsymbol{e}_{\mathrm{Qfa}} & 1
\end{array}\right]\left[\begin{array}{l}
\boldsymbol{Q}_{c} \\
\boldsymbol{Q}_{a} \\
Q_{f}
\end{array}\right]=\boldsymbol{O}
$$

where

$$
\begin{aligned}
& \left.\left[\begin{array}{ll}
\boldsymbol{E}_{Q c} & \boldsymbol{E}_{Q a}
\end{array}\right]=\left[\left[\begin{array}{ccc}
-1 & \cdots & -1
\end{array}\right]_{1 \times n}\right] \quad \boldsymbol{I}_{(n+1)}\right], \quad \boldsymbol{Q}_{c}=\left[\begin{array}{lll}
Q_{1} & \cdots & Q_{n}
\end{array}\right]^{T} \\
& \left.\left[\begin{array}{ll}
\boldsymbol{e}_{\mathrm{Qfc}} & \boldsymbol{e}_{\mathrm{Qfa}}
\end{array}\right]=\left[\begin{array}{lll}
{[1} & \cdots & 1
\end{array}\right]_{1 \times n}\left[\begin{array}{lll}
0 & \cdots & 0
\end{array}\right]_{1 \times(n+1)}\right], \quad \boldsymbol{Q}_{a}=\left[\begin{array}{llll}
Q_{n+1} & Q_{v 1} & \cdots & Q_{v n}
\end{array}\right]^{T}
\end{aligned}
$$

Based on Kirchhoff's voltage law, we have

$$
\left[\begin{array}{ccc}
\boldsymbol{E}_{H c} & \boldsymbol{E}_{H a} & \boldsymbol{O}_{(n-1)^{* 1}} \\
\boldsymbol{e}_{H f c} & \boldsymbol{e}_{H f a} & \boldsymbol{\eta}
\end{array}\right]\left[\begin{array}{l}
\boldsymbol{H}_{c} \\
\boldsymbol{H}_{a} \\
H_{f}
\end{array}\right]=\boldsymbol{O}
$$

where

$$
\begin{gathered}
{\left[\begin{array}{ll}
\boldsymbol{E}_{H c} & \boldsymbol{E}_{H a}
\end{array}\right]=\boldsymbol{O}, \quad \boldsymbol{H}_{c}=\left[\begin{array}{lll}
H_{1} & \cdots & H_{n}
\end{array}\right]^{T}, \quad \boldsymbol{\eta}=\left[\begin{array}{lll}
1 & \cdots & 1
\end{array}\right]_{1 \times n}^{T}} \\
{\left[\begin{array}{ll}
\boldsymbol{e}_{H f c} & \boldsymbol{e}_{H f a}
\end{array}\right]=\left[\begin{array}{llll}
\boldsymbol{I}_{n} & {\left[\begin{array}{lll}
1 & \cdots & 1
\end{array}\right]_{1 \times n}^{T}} & \boldsymbol{I}_{n+1}
\end{array}\right], \quad \boldsymbol{H}_{a}=\left[\begin{array}{llll}
H_{n+1} & H_{v 1} & \cdots & H_{v n}
\end{array}\right]^{T}}
\end{gathered}
$$

$H_{f}$ is the pressure drop of the feedwater pump branch. $H_{f}$ can be expressed as $H_{f}=-H_{d}+R_{f} Q_{f}$. So we can obtain

$$
\left\{\begin{array}{c}
\boldsymbol{Q}_{f}=\boldsymbol{e}_{Q f} \boldsymbol{Q}=\boldsymbol{e}_{Q f c} \boldsymbol{Q}_{c} \\
\boldsymbol{Q}_{c}=\boldsymbol{A}_{c} \boldsymbol{Q}_{c D}^{2} \boldsymbol{R}_{c}+\boldsymbol{A}_{a} \boldsymbol{Q}_{a D}^{2}+\boldsymbol{B}_{c} \boldsymbol{Q}_{c}+\boldsymbol{C}_{c} \boldsymbol{H} \\
\boldsymbol{Q}_{a}=-\boldsymbol{E}_{Q c} \boldsymbol{Q}_{c} \\
\boldsymbol{H}_{a}=\boldsymbol{\zeta}_{R Q c} \boldsymbol{Q}_{c D}^{2} \boldsymbol{R}_{c}+\boldsymbol{\zeta}_{R Q a} \boldsymbol{Q}_{a D}^{2} \boldsymbol{R}_{a}+\boldsymbol{\zeta}_{Q c} \boldsymbol{Q}_{c}+\boldsymbol{\zeta}_{d} \boldsymbol{H}_{d} \\
\boldsymbol{H}_{c}=\boldsymbol{E}_{Q c}^{T}\left(\boldsymbol{\zeta}_{R Q c} \boldsymbol{Q}_{c D}^{2} \boldsymbol{R}_{c}+\boldsymbol{\zeta}_{R Q a} \boldsymbol{Q}_{a D}^{2} \boldsymbol{R}_{a}\right)+\left(\boldsymbol{E}_{Q c}^{T} \boldsymbol{\zeta}_{Q c}-R_{f} \boldsymbol{S}_{Q c}\right) \boldsymbol{Q}_{c}+\left(\boldsymbol{E}_{Q c}^{T} \boldsymbol{\zeta}_{d}+\boldsymbol{S}_{d}\right) \boldsymbol{H}_{d}
\end{array}\right.
$$

where

$$
\begin{aligned}
& {\left[\begin{array}{ll}
\boldsymbol{R}_{c}^{T} & \boldsymbol{R}_{a}^{T}
\end{array}\right]=\left[\begin{array}{lll}
R_{1} & \cdots & R_{n}
\end{array}\right]\left[\begin{array}{llll}
R_{n+1} & R_{v 1} & \cdots & R_{v n}
\end{array}\right]^{T}, \quad \boldsymbol{Q}_{c D}^{2}=\operatorname{diag}\left\{Q_{1}\left|Q_{1}\right|, \cdots, \quad Q_{n}\left|Q_{n}\right|\right\}} \\
& \boldsymbol{Q}_{a D}^{2}=\operatorname{diag}\left\{Q_{n+1}\left|Q_{n+1}\right|, \quad Q_{v 1}\left|Q_{v 1}\right|, \quad \cdots, \quad Q_{v n}\left|Q_{v n}\right|\right\}, \quad \boldsymbol{S}_{Q c}=\boldsymbol{e}_{Q f c}^{T} \boldsymbol{e}_{Q f c}, \quad \boldsymbol{S}_{d}=\boldsymbol{e}_{Q f c}^{T}
\end{aligned}
$$

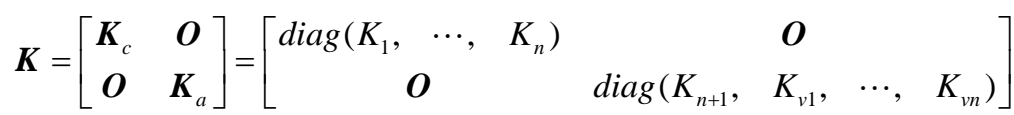

$$
\begin{aligned}
& \boldsymbol{\xi}_{R Q c}=\left(\boldsymbol{E}_{Q c} \boldsymbol{K}_{c} \boldsymbol{E}_{Q c}^{T}+\boldsymbol{K}_{a}\right)^{-1} \boldsymbol{E}_{Q c} \boldsymbol{K}_{c}, \quad \boldsymbol{\xi}_{R Q a}=\left(\boldsymbol{E}_{Q c} \boldsymbol{K}_{c} \boldsymbol{E}_{Q c}^{T}+\boldsymbol{K}_{a}\right)^{-1} \boldsymbol{K}_{a} \\
& \boldsymbol{\xi}_{Q c}=R_{f}\left(\boldsymbol{E}_{Q c} \boldsymbol{K}_{c} \boldsymbol{E}_{Q c}^{T}+\boldsymbol{K}_{a}\right)^{-1} \boldsymbol{E}_{Q c} \boldsymbol{K}_{c} \boldsymbol{S}_{Q c}, \quad \boldsymbol{\xi}_{d}=-\left(\boldsymbol{E}_{Q c} \boldsymbol{K}_{c} \boldsymbol{E}_{Q c}^{T}+\boldsymbol{K}_{a}\right)^{-1} \boldsymbol{E}_{Q c} \boldsymbol{K}_{c} \boldsymbol{S}_{d} \\
& \boldsymbol{A}_{c}=-\left(\boldsymbol{K}_{c}^{-1}+\boldsymbol{E}_{Q c}^{T} \boldsymbol{K}_{a}^{-1} \boldsymbol{E}_{Q c}\right)^{-1}, \quad \boldsymbol{A}_{a}=\left(\boldsymbol{K}_{c}^{-1}+\boldsymbol{E}_{Q c}^{T} \boldsymbol{K}_{a}^{-1} \boldsymbol{E}_{Q c}\right)^{-1} \boldsymbol{E}_{Q c}^{T} \\
& \boldsymbol{B}_{c}=-\left(\boldsymbol{K}_{c}^{-1}+\boldsymbol{E}_{Q c}^{T} \boldsymbol{K}_{a}^{-1} \boldsymbol{E}_{\mathrm{Qc}}\right) \boldsymbol{S}_{\mathrm{Qc}}, \quad \boldsymbol{C}_{c}=\left(\boldsymbol{K}_{c}^{-1}+\boldsymbol{E}_{Q c}^{T} \boldsymbol{K}_{a}^{-1} \boldsymbol{E}_{Q c}\right)^{-1} \boldsymbol{S}_{d}
\end{aligned}
$$

From Equation (4), we can obtain the mass flow rates and pressure drops of the branch in the SSFFN, it is the differential-algebraic model of the SSFFN. If modules' number $n$ is given, it is clear that the topology of the SSFFN can be determined. So modules' number $n$ is important to determine the SSFFN dynamics.

\section{Control Scheme}

In actual engineering, the mass flow rates and pressure drops should reach the expectation values. From Equation (4), a differential-algebraic model of the SSFFN has been established. $\boldsymbol{R}, \boldsymbol{K}$ and $H_{d}$ is the input of the model. We 
can adjust the opening of feedwater valves to change mass flow rates in the NSSS modules and control the main steam pressure drop of the steam turbine generator set by adjusting the pressuer head of feedwater pump. A PI control scheme based on above has been established and its structure can be seen in Figure 3. We can use controller $H_{d}$ to control main pressure drop $H_{n+1}$ of the steam turbine generator set and controllers $R_{v i}(i=1, \cdots, n)$ to control mass flow rates $Q_{i}(i=1, \cdots, n)$ in NSSS modules.

To overcome the pipe sensor noise, a section of inertia link is added in controllers, which plays an role of low pass filter. Controllers shown in Figure $\mathbf{3}$ can guarantee the global asymptotic stability of the system, which can can be proved by Lyapunov energy function. In addition, the simulation results in this paper can also verify the above control scheme.

\section{Implementation and Simulation}

\subsection{Implementation}

In MATLAB $\backslash S I M U L I N K$ environment, the model has been implemented by using the programming language M code based on the principles of Level-2 S-Function. The model provides parameters interface in order to let users to define the number of NSSS modules and structure of the SSFFN. The users must input the parameters, such as the nodes' number, the feeding-pump branches' number, the rest branches' number and the matrices of KCL, which depends on the number of NSSS modules, to initialize the model. The users can add other simulation modules to make real-time simulation.

\subsection{Simulation}

In MATLAB $\backslash S I M U L I N K$ environment, the model has been implemented by using the programming language M code based on the principles of Level-2 S-Function (Figure 4). The model provides parameters interface in order to let users to define the number of NSSS modules and structure of the SSFFN. The users must input the parameters, such as the nodes' number, the feeding-pump branches' number, the rest branches' number and the matrices of KCL, which depends on the number of NSSS modules, to initialize the model. The users can add other simulation modules to make real-time simulation.

This paper has made simulation of SSFFN of MHTGR plant, which has two NSSS modules and uses the common feedwater pump to feed for the two. In this network, the mass flow rate is controlled by the feeding valve, making topology analysis on the structure of the SSFFN and setting inertia coefficients of the branch excluding feeding-pump branch $K$ as diag $(0.1 ; 0.1 ; 0.1 ; 0.1 ; 0.1)$. To simulate the real operation ,conditions can be set as follow, the time of simulation $t$ is 3000s, the initial value of pressure head of feedwater pump $H_{d}$ is $25 \mathrm{Mpa}$, the resistance of branch $R_{1}, R_{2}, R_{3}, R_{f}$ is $0.00118,0.00118,0.0038,0.00044$, the initial value of $R_{v 1}, R_{v 2}$ is

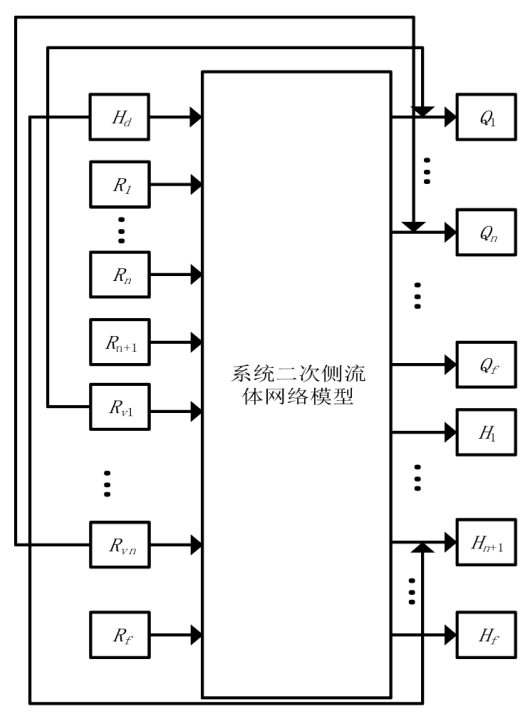

Figure 3. PI controllers.
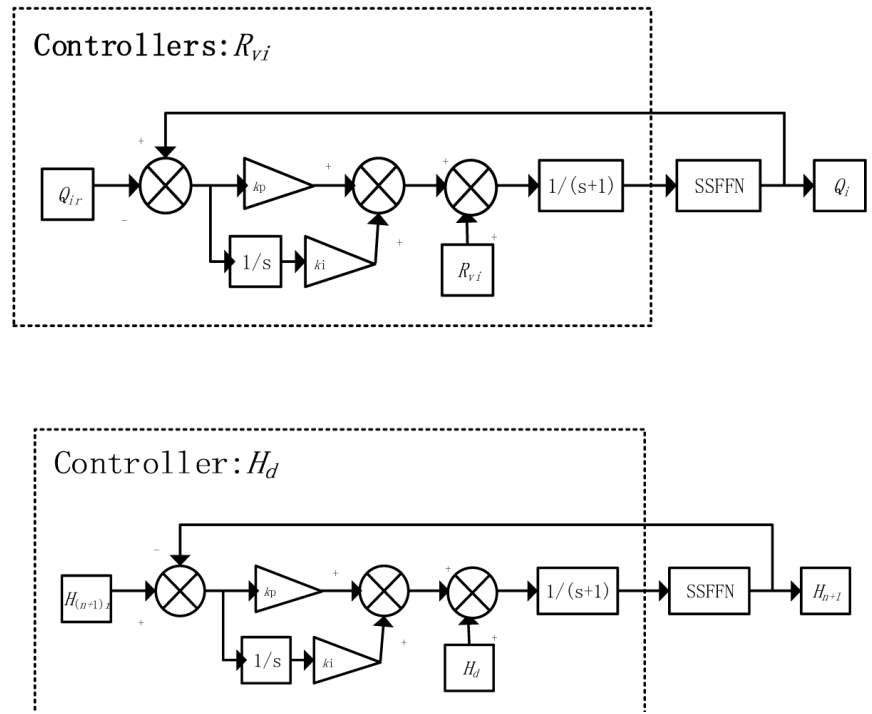


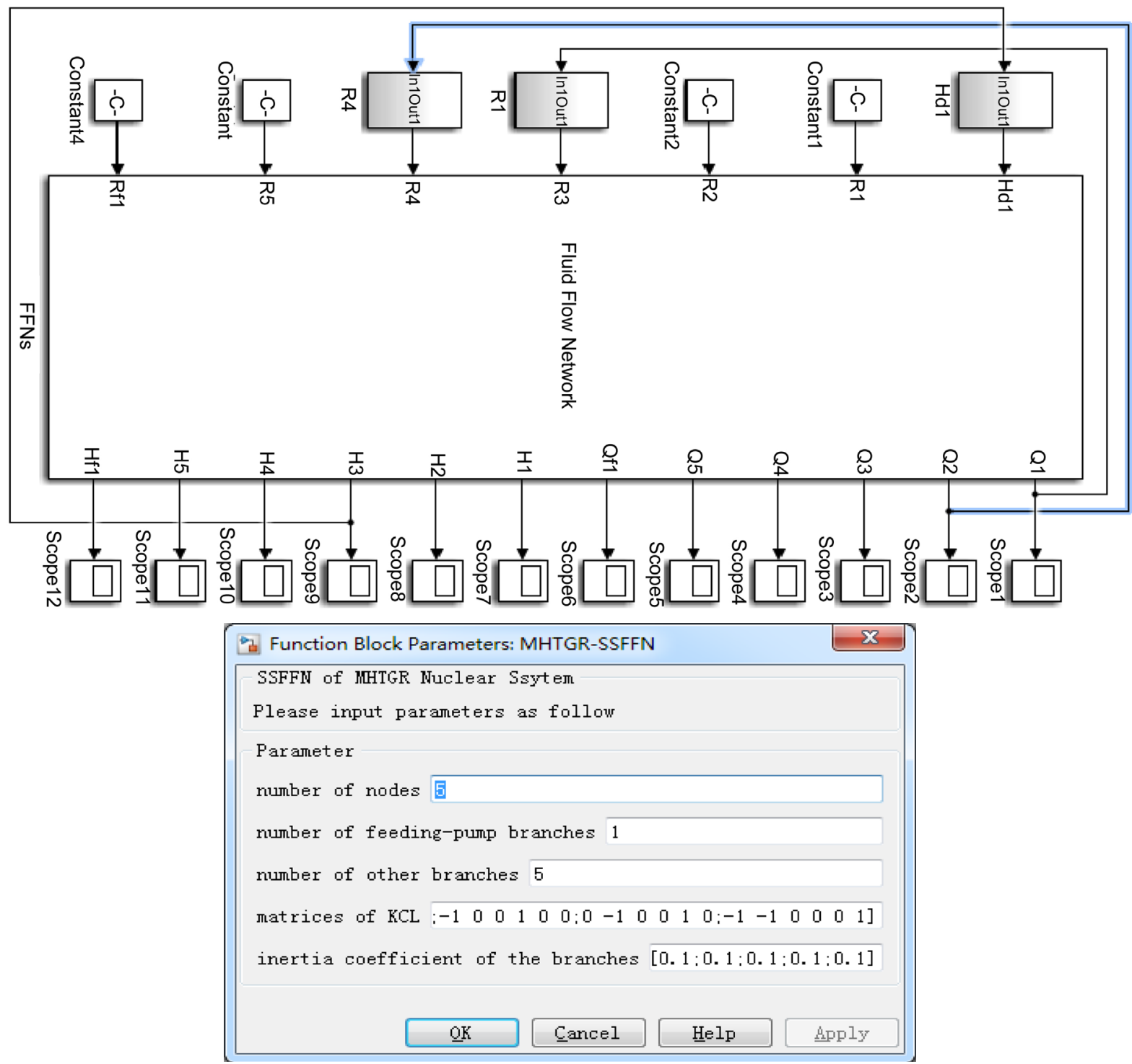

Figure 4. Encapsulation model and its parameters interface.

0.00118, 0.00118. The main steam pressure drop of the steam turbine generator set remains 13.9 Mpa. A case study is given to show the performance of the model. In this case, the mass flow rate of 1 \#NSSS remains $96 \mathrm{~kg} / \mathrm{s}$ in $1000 \mathrm{~s}$, it will drop to $90 \mathrm{~kg} / \mathrm{s}$ at $1000 \mathrm{~s}$. Controller $H_{\mathrm{d}}: k_{\mathrm{p}}=1$, $k_{\mathrm{i}}=1$; Controller $R_{v 1}: k_{\mathrm{p}}=0.0001, k_{\mathrm{i}}=0.0001$; The mass flow rates, pressure drops and control inputs are respectively shown in Figure 5.

The mass flow rate of $1 \#$ NSSS module, $Q_{1}$, is controlled by the feeding valves. The drop of mass flow rate is caused by the decrease of the valve opening, thus resulting in increase in the branches' resistance and pressure head of feedwater pump. Because of the controller, the main steam pressure drop, $H_{3}$ remians the initial value. The results show good robustness of controllers.

\section{Conclusion}

The SSFFN of MHTGR plant has features, i.e. strong-coupling and nonlinear, because multiple NSSS modules use the common feedwater system to drive the same steam turbine generator set. A wide range of power switching operation may cause unsteady fluid flow in the network, which may destroy working components. This problem must be avoided in order to ensure the system's safety. It is meaningful to make analysis on dynamics of the SSFFN. Branch dynamics and network's structure features plays an important role in modeling SSFFN. 

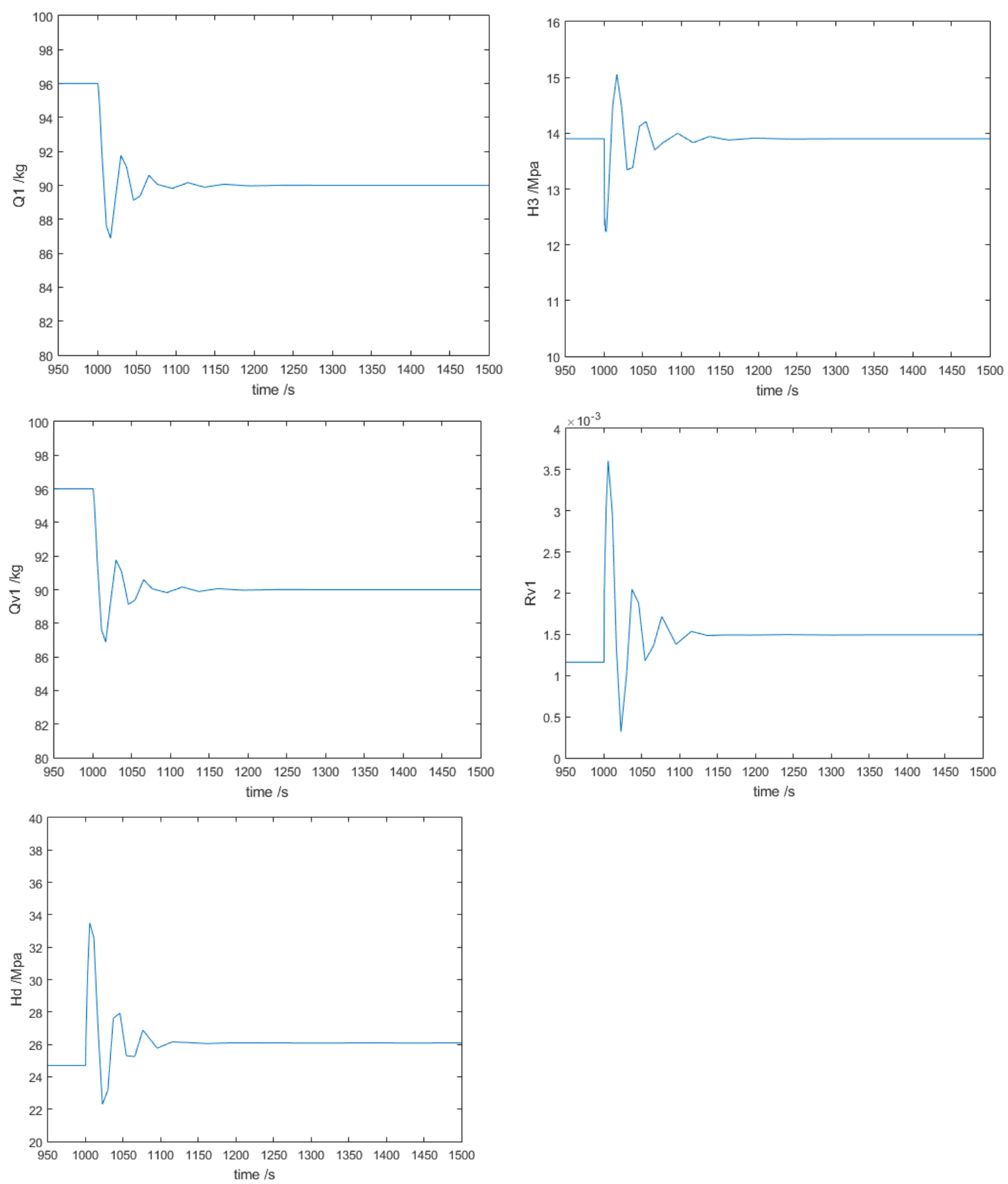

Figure 5. Case results.

Base on KCL and KVL, this paper designed a differential-algebraic model for SSFFN. Based on the model, this paper designed PI controllers to promise the closed system globally asymptotically stable. In MATLAB $\backslash$ SIMULINK environment, the paper made implementation of the model and designed a good human-machine interface for users to define the structure of the SSFFN at ease. To proof the model and the controller, this paper made simulation of SSFFN of a MHTGR plant which has two modules and uses one common feedwater pump feeding for the two. The results efficiently reflect the controllers' good performance. The simulation platform established in this paper may help engineers to make integral coefficient test and choose the best one, which is 
actually based on engineers' experiences. Also, the simulation platform can be used to control SSFFN of MHTGR plant which has more modules.

\section{Acknowledgements}

This work was supported in part by National S\&T Major Project under Grant ZX06901, and in part by Natural Science Foundation of China (NSFC) under Grant 61374045.

\section{References}

[1] Zhang, Z., Wu, Z., Wang, D., et al. (2009) Current Status and Technical Description of Chinese $2 \times 250$ MW $_{\text {th }}$ HTRPM Demonstration Plant. Nuclear Engineering and Design, 239, 1212-1219. http://dx.doi.org/10.1016/j.nucengdes.2009.02.023

[2] Lohnert, G.H. (1990) Technical Design Features and Essential Safety-Related Properties of the HTR-Module. Nuclear Engineering and Design, 121, 259-275. http://dx.doi.org/10.1016/0029-5493(90)90111-A

[3] Economic Potential of Modular Reactor Nuclear Power Plants Based on the Chinese HTR-PM Project

[4] Hu, Y., Koroleva, O.I. and Krstić, M. (2003) Nonlinear Control of Mine Ventilation Networks. Systems \& control letters, 49, 239-254. http://dx.doi.org/10.1016/S0167-6911(02)00336-5

[5] Izadi, G. and Elsworth, D. (2014) Reservoir Stimulation and Induced Seismicity: Roles of Fluid Pressure and Thermal Transients on Reactivated Fractured Networks. Geothermics, 51, 368-379. http://dx.doi.org/10.1016/j.geothermics.2014.01.014

[6] Aldridge, M.D., Swartwout, R.E., Smith Jr., N.S., et al. (1976) Electronic Monitoring and Control of Mine Ventilation. Proceedings of the 3rd WVU Conference Coal Mine Electrotechnology, Morgantown.

[7] Hu, Y., Koroleva, O.I. and Krstic, M. (2002) Control Design for Mine Ventilation Network Systems. Proceedings of the 41st IEEE Conference on Decision and Control, 1, 543-548.

[8] Kocic, D.D. (1979) On the Autonomy of Local Systems in Mine Ventilation Control. 2nd Mine Ventilation Congress, Reno.

[9] Hu, Y., Koroleva, O.I. and Krstić, M. (2003) Nonlinear Control of Mine Ventilation Networks. Systems \& control letters, 49, 239-254. http://dx.doi.org/10.1016/S0167-6911(02)00336-5

[10] Dong, Z. (2015) Dissipation Analysis and Adaptive Control of Fluid Networks. The 2015 American Control Conference, Chicago.

\section{Submit or recommend next manuscript to SCIRP and we will provide best service for you:}

Accepting pre-submission inquiries through Email, Facebook, LinkedIn, Twitter, etc.

A wide selection of journals (inclusive of 9 subjects, more than 200 journals)

Providing 24-hour high-quality service

User-friendly online submission system

Fair and swift peer-review system

Efficient typesetting and proofreading procedure

Display of the result of downloads and visits, as well as the number of cited articles

Maximum dissemination of your research work

Submit your manuscript at: http://papersubmission.scirp.org/ 